\title{
Apocalípticos y catequéticos \\ Un giro religioso-político para la filosofía contemporánea
}

\author{
DIEGO FONTI* \\ Conicet-Universidad Católica de Córdoba (Argentina) \\ diegofonti@gmail.com
}

\begin{abstract}
Resumen
La experiencia religiosa y la experiencia política han subsistido, a pesar de que la Modernidad y de que nuestra época pretendió a menudo reducir lo político a un campo de relaciones técnicas y procedimientos administrativos. En este contexto es necesario formular la pregunta filosófica por el valor y legitimidad de la relación entre ambos campos en su versión contemporánea. En este artículo se indaga, en primer lugar, en la noción de legitimidad a partir de la obra de Schmitt, para comprender los orígenes y la dependencia simbólica de la mencionada relación. Esta indagación mostrará una tensión entre dos experiencias: la expectativa de lo apocalíptico y la "administración" del tiempo (katechon), que atraviesa toda la reflexión teológica. En segundo lugar, se verá a partir de Voegelin el riesgo necesario que se corre en toda acción política. Finalmente, se mostrará a partir de Taubes y Metz cómo la tradición monoteísta de la memoria de la Ley y del sufrimiento postula el peso de una autoridad que permite un horizonte posible desde el cual juzgar y limitar los déficits de toda acción político-religiosa, y cómo se puede sostener la tensión entre ambas experiencias.
\end{abstract}

Palabras clave: religión; política; teología política; legitimidad.

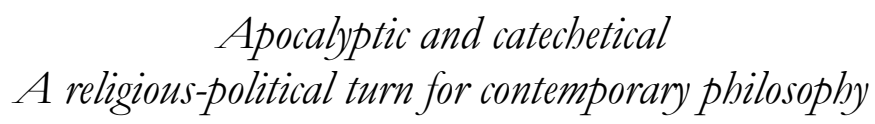

\begin{abstract}
Religious experience and political experience have survived, despite the fact that Modernity and our age have often tried to reduce the political to a field of technical relations and administrative procedures. In this context, it is necessary to formulate the philosophical question about the value and legitimacy of the relationship between both fields in its contemporary version. This article investigates, firstly, the notion of legitimacy based on Schmitt's work, to understand the origins and symbolic dependence of the aforementioned relationship. This inquiry will show a tension between two experiences: the expectation of the apocalyptic and the "administration" of time (katechon), which runs through all theological reflection. Second, it will be seen from Voegelin the necessary risk that is run in all political action. Finally, it will be shown from Taubes and Metz how the monotheistic tradition of the memory of the Law and of suffering postulates the weight of an authority that allows a possible horizon from which to judge and limit the deficits of all political-religious action, and how the tension between the two experiences can be sustained.
\end{abstract}

Key words: religion; politics; political theology; legitimacy.

* Doctor en Filosofía por la Albert-Ludwigs Universität Freiburg (Alemania). Investigador de CONICET. Catedrático e investigador de la Universidad Católica de Córdoba. Este trabajo se enmarca en el Proyecto de Investigación Plurianual titulado "Legitimidad y normatividad. El problema en la filosofía y en las ciencias sociales y políticas latinoamericanas". 


\section{SOBRE POLÍTICA, RELIGIÓN Y DESENCANTO}

Hay términos que a simple vista parecen pertenecer a paradigmas acabados. Apocalíptico y catequético lo parecen, a menos que se los use como adjetivación irónica o simplemente denigrante. Y sin embargo las ideas de una experiencia que llega y se revela excediendo la posibilidad de dominio por parte de los sujetos que la vivencian, y de un modo de "negociar" entre la vivencia y demanda de esa experiencia y las demandas, poderes y posibilidades del mundo, son ideas que provienen de cierta experiencia religiosa (o al menos en general del orden simbólico), y reaparecen una y otra vez en la historia del pensamiento y la praxis. Los pensadores de la "secularización" moderna sostienen que el avance de la ciencia y las concepciones ético-políticas modernas son modos particulares de autonomizar el conocimiento y la acción humana respecto de toda posición trascendente, lo que confirma el des-encantamiento del mundo que Max Weber (2014: 384) había identificado como proceso transversal de la modernidad.

Sin embargo, en la época que Heidegger (1996: 63ss) denomina "de la imagen del mundo", suceden al menos dos situaciones con el tipo de experiencia que podemos denominar "religiosa". En esta época encontramos un modo de comprender la verdad como manifestación de una ciencia y una técnica modernas que se independizan en su acción, donde se subordina todo conocimiento a la cuantificación, y toda expresión artística o del obrar humano a disciplinas como la estética o el análisis cultural. También, según Heidegger, se opera una "desdivinización o pérdida de dioses", transformando sus restos en análisis mitológico o científico de esos discursos y experiencias (Heidegger, 1996: 64). Todas estas características están atravesadas por un modo de entender el conocimiento como cuantificación y puesta a disposición del mundo por parte del sujeto. Pero al mismo tiempo podemos ver una segunda y paradojal situación en el plano estrictamente religioso. Las "nuevas" religiosidades y manifestaciones religiosas, por ejemplo, cercanas a movimientos evangélicos y pentecostales, retoman algunas de las características que Weber encontraba en el espíritu original de capitalismo, pero en un marco económicamente neoliberal y moralmente conservador. Sin perder el modelo de dominio del mundo, parecen forzar la experiencia religiosa en el modelo de conquista y progreso, o como lo plantea Enrique Dussel, representan el modelo de consumo legitimado por una conciencia de la divinidad que exige y garantiza el éxito social y económico. Dussel (2020: $127 \mathrm{ss}$ ) ha mostrado consistentemente las raíces teológicas de las diversas posiciones políticas, y recientemente ha actualizado esa comprensión teniendo en cuenta los giros y las intervenciones políticas de sectores 
evangélicos, pentecostales y de parcialidades católicas neoconservadoras (Dussel, 2019). Estos sectores, lejos de la secularización y del desencantamiento del mundo, identifican la acción divina en las más mundanas decisiones y resultados económicos y políticos. La paradoja está en que estos grupos asumen algunas de las pretensiones modernas de dominio del mundo y consumo capitalista, pero sin adscribir a otras de las demandas "liberales" modernas, vinculadas por ej. a las decisiones sobre sí de los sujetos. Pero, además, y en paralelo, estos grupos son reactivos ante las iniciativas de los Estados modernos respecto de los derechos "liberales", aunque sostienen su estructura económica fundamental, su modelo de reproducción de la mercancía, acumulación y consumo, etc.

En una primera lectura superficial, esta situación podría entenderse como epígono de la antigua tensión cristiana entre poderes del mundo y confesión religiosa, la misma que suscitó a lo largo de la historia notables movimientos apocalípticos. Y al mismo tiempo debería verse como deriva del monoteísmo mismo en tanto dispositivo de secularización y racionalización del mundo, por su extrapolación del principio divino a un ámbito trascendente y su mundanización de las condiciones de acceso, comprensión y trato del mundo ${ }^{1}$. Sin embargo, las críticas a la modernidad antes mencionadas no son capaces de dar cuenta de algunos aspectos emancipatorios que atraviesan los sucesivos discursos "apocalípticos", ni de sus posibilidades en esas mismas condiciones contemporáneas, en tanto podrían precisamente alimentar ciertos rasgos que esas mismas condiciones modernas dejaron desatendidos. Los nombres de los pensadores "apocalípticos" - entendiendo el término en sentido estricto, y no en el más vulgar de pesimismo religioso o catástrofe radicalson importantes, y algunos de ellos son parte de este trabajo. Pero no sólo en la filosofía o la teología se halla este movimiento. Como vemos especialmente en América Latina, se recurre al vínculo con lo religioso cuando se reclama por justicia o memoria, y se lo hace tanto en vistas a un modelo de revelación y escatología, Apocalipsis, como a una estrategia de retención de un legado y gestión del tiempo, Katechon.

Paradojalmente esto sucede en una época en que los movimientos políticos y religiosos más entusiastas parecían haber acabado, como lo podemos ver en dos claras expresiones de las últimas décadas. Por un lado, y partir de lo que se denominó "posmodernidad", se adoptó como lugar común la afirmación de la "caída de los grandes relatos" (Lyotard,

1 Es imposible abarcar aquí los hitos de ese proceso, que corre en paralelo al análisis principal del libro de Habermas Auch eine Geschichte der Philosophie (2019) y que reconstruye las relaciones entre creer y saber como motor de los procesos de aprendizaje y de la progresiva secularización cognitiva, ética y política de occidente. 
1979). Se trataba de aquellas comprensiones omniabarcativas del mundo -sea por su posición simbólica o "científica"- que pretendían mostrar no sólo la configuración del mundo y su sentido, sino además exponer desde allí las posibilidades de acción humanas. No sólo se incluían en esa lista al cristianismo y al comunismo, sino a la ilustración misma. Más que proyectos religiosos o científicos, se trataba de espacios simbólicos, en que algunos de los más poderosos deseos y necesidades humanas adquirían un lenguaje, un horizonte, un marco académico, y un modelo práctico de aplicación. No hace falta hacer aquí una historia del fracaso de estas estructuras, sino que basta con afirmar que esas esperanzas caducaron en sus formas canónicas. Fueron tradiciones aparentemente de corta duración. La apariencia consiste en que algunas de sus raíces todavía conectan con necesidades y deseos humanos fundamentales. Por eso, la pregunta por la caída de esos relatos capaces de generar esperanzas aplica todavía en general a aquellos marcos simbólicos con que los humanos intentamos no sólo entender cómo funciona el mundo, sino cuál es su sentido, porqué involucrarnos en el mismo, y qué esperar de este compromiso.

En segundo lugar, hasta hace relativamente poco parecía un lugar común también hablar de desencanto ante la democracia. Por supuesto que dicho desencanto sólo era tal para quienes la concebían como algo más que una técnica de gestión de la política ${ }^{2}$. Ese concepto tan reductivo no se halla todavía en Weber, porque mientras que para él las formas de racionalización de la vida social conllevaban un "desencantamiento", -en el sentido que las figuras carismáticas o portadoras de un saber sagrado o metafísico perdían credibilidad y poder-, pensaba a pesar de ello que había otras formas de acción no técnicas pero también racionales, como aquellas orientadas por valores, que también permeaban la política. $\mathrm{Y}$, sin embargo, una consecuencia histórica lógica de ese desencantamiento fue la reducción de esas acciones orientadas por sentidos o valores a la esfera individual, o a lo sumo de pequeños colectivos o asociaciones. Pero en la política social global sí mostraba necesario comprender como objetivo fundamental el control técnico o burocrático de los procesos (Weber, 2014: 299ss). Así, no sólo cae el horizonte mítico o simbólico que cohesionaba y orientaba las actividades sociales, los reclamos por derechos, y la legitimación del poder, sino también el intento

2 Una referencia significativa de este momento de desencanto es el Nro. 15 de Nombres. Revista de Filosofía, Universidad Nacional de Córdoba, publicado en octubre de 2000. 
del racionalismo moderno que buscaba proyectar la interpretación premoderna de estos elementos en las instituciones modernas ${ }^{3}$.

A estos desencantos de la caída de los relatos omniabarcativos y de una comprensión de lo político, se suma el de cierta experiencia religiosa. La religión y su exposición intelectual, la teología, se ven en dificultades epistemológicas para validar afirmaciones que corresponden al campo de creencias o sentidos no refutables o justificables en el ámbito experimental, a lo que se suma su descrédito por los vínculos con aparatos inmorales de poder. Pero como indicábamos antes, el asunto es muy complejo, pues no faltan voces que afirman que asistimos a un "revival" de diversas religiosidades. La modernidad ilustrada confiaba que la búsqueda de respuestas tradicionalmente atribuidas a la religión habría de fracasar cuando las mismas pasasen a manos de la ciencia (Lübbe, 1986: 91ss) -y esta tuviese resultados-, pero esta confianza no parece haberse realizado. Más aún, a menudo aparecen grupos en que se identifican aspectos de las experiencias religiosas que corresponden a las facetas más cuestionables de la experiencia humana: grupos que operan en pos de la obediencia irreflexiva de sus subordinados, o que niegan todo valor a los conocimientos y posibilidades técnicas y científicas, o simplemente que niegan todo lo bueno y bello que todavía puede dar de sí la humanidad. Habría así un doble desencanto: el desencanto por la caída de la visión "tradicional" de la experiencia religiosa, fruto del avance de la modernidad, y el desencanto más actual de quienes valoran todavía la experiencia religiosa, pero la ven confinada a espacios inaceptables para un pensamiento contemporáneo que haya asumido las transformaciones de la modernidad.

Es verdad que el desencanto mismo debe ser puesto entre paréntesis, ya que hay nuevas formas de lo religioso, y nuevas formas de lo político- particularmente en América Latina -que frente al desencanto generan entusiasmo. Se da un giro religioso-político, pero no sabemos hacia dónde puede o debe conducir ${ }^{4}$. Entonces, ¿cómo pensar filosóficamente

3 Un autor clave en esta comprensión es Hermann Cohen, quien en su elogio del idealismo muestra que recién la evolución prusiana del mismo, con su fusión de idealismo heleno y herencia judeocristiana, dan lugar a un sistema pleno. Cohen muestra cómo en el Deuteronomio las nuevas estructuras legales morales "son invocadas como las creaciones de la nueva religión. Así surge una relación entre la religión y la política social. Pues los 'preceptos y normas', que deben demostrar la 'sabiduría' de este pueblo, como también el liderazgo de Dios, son estructuras jurídicas destinadas a fundar y consolidar tanto la moralidad social como la individual" (Cohen, 2004: 19). Pero pocos párrafos después afirma el vínculo entre profetismo y política, y sin embargo el profetismo es lo contrario a un campo tranquilo y ordenado, más aún, es el lugar de "creatividad judía", donde el vínculo con los poderes se vuelve siempre cuestionable.

4 Es preciso tomar con cuidado el término teológico-político, por dos razones: ante todo la teología política se auto-comprende como teología fundamental (Manemann, 
ambos, desencanto y entusiasmo, de un modo tal que ni produzca un "reencantamiento" del mundo ni un tipo de "endiosamiento" rayano en la locura, el conservadorismo integrista u otro intento de opresión? Y al mismo tiempo, ¿cómo pensar de un modo que no sea la simple validación fáctica de un estado político determinado? Una respuesta, por ejemplo, la ofrece Lübbe: la religión es imperecedera porque tiene que ver con déficits y limitaciones antropológicas no eliminables -la finitud, la incertidumbre, la muerte- y por ello frente a las mismas el tipo de "superación de la contingencia" (1986: 160) religioso no es subsumible bajo la ciencia, mucho menos bajo la política. Más aún, mantener cada una de las tres actividades -ciencia, política, religión-reducidas a su espacio, es un aporte que podría provenir de la religión, ya que el trasvase de potestades generó siempre situaciones de violencia y sufrimiento. El problema con esta respuesta es que no ve que a menudo esos trasvases son necesarios, en tanto fuerzan a los diversos campos a asumir los desafíos y exigencias provenientes de los otros. Además. obviamente lo religioso ha funcionado como mucho más que una superación de la contingencia.

Luego de presentar una perspectiva de las tensiones entre ambos elementos siguiendo a Habermas, y en vistas a intentar una respuesta que dé cuenta de esta relación -corriendo el riesgo de un planteo excesivamente esquemático, pero que bien puede servir a modo de hitos o indicadores en una hoja de ruta para abordar- pretendo aquí tomar tres temas que sirven para pensar en un marco contemporáneo la relación entre experiencia religiosa y política. Ante todo, partiré de Schmitt y abordaré el problema de la legitimidad de Oikumene y Ekklesia, o el conflicto de las potestades. Luego analizaré lo que Voegelin llama "búsqueda del orden en la historia", como elemento vinculante de política y religión. Y finalmente, tomando a Taubes y Metz, la cuestión de la memoria de la ley y de la pasión como motor de la responsabilidad político-religiosa. Todo esto para concluir con un aspecto que considero fundante incluso del deseo más elemental por abordar esta tarea: la autoridad de los que sufren, como lugar para recuperar un vínculo legítimo de esta relación y como respuesta a las tensiones identificadas por Habermas y los peligros que se desprenden de Schmitt y Voegelin.

\footnotetext{
2002: 2), mientras que el abordaje aquí propuesto es filosófico y por lo tanto el término es tomado desde esa dimensión, y segundo, porque aunque sea la teología el campo conceptual de la mayoría de los autores y de las nociones, no quiero limitarme a ese campo de elaboración, y en este sentido "lo religioso" me parece capaz de incluir la reflexión teológica al mismo tiempo que otras experiencias religiosas.
} 
Una forma de plantear y delimitar el problema que nos convoca puede hallarse en la conferencia que presentó Habermas para el encuentro de 2009 con Butler, Taylor y West, patrocinado entre otros por las universidades de Nueva York y Stony Brook. Habermas parte de una constatación: con la globalización económica capitalista, algunas intenciones fundamentales de la política, hasta el período de los estados de bienestar inclusive, han quedado inutilizadas. Las ideas de integración social y autodeterminación han sido subyugadas a la administración de la vida regida por imperativos económicos, lo que condujo al desánimo respecto de las posibilidades de la política y a un desencanto respecto de la democracia misma.

Lo religioso y lo político son dos órdenes que marcaron la esfera pública, que para Habermas configura el ámbito por antonomasia de debate y legitimación de las diversas pretensiones de validez a partir de la modernidad. Los estudios de Habermas sobre la opinión pública le llevaban ya a pensar modelos normativos y un tipo de ideal comunicativo, en tanto espacio diverso del aparato estatal -y de las instituciones religiosas- pero capaz de incidir sobre ellos mediante sus deliberaciones y el tipo de razones que se proponían. Sin embargo, también este ámbito ha sido afectado de modo notable por el avance de la racionalidad capitalista. Pero lo interesante que surge en el marco burgués de la aparición de la opinión pública, según Habermas, es la idea de dejarse llevar por la fuerza del mejor argumento y con mayor capacidad de dar cuenta de las pretensiones de validez de sus afirmaciones, y por ende como contraposición a tipos de coacción a menudo procedentes de las esferas ideológicas y religiosas. Esa toma de distancia de Habermas respecto de lo religioso se ha manifestado de diversos modos, y al mismo tiempo le ha provisto a los discursos con compromisos religiosos de una serie de criterios para traducir sus afirmaciones en términos seculares viables para quienes no comparten esos compromisos.

El problema está en que a menudo se piensa que el estado liberal secular tiene precondiciones que le dieron a luz y que no puede garantizar, puesto que provienen de un contexto simbólico anacrónico. La respuesta habermasiana a este punto es que la apertura de las legitimaciones del estado constitucional moderno y republicano puede, más allá de sus precondiciones religiosas, alcanzar un estado de auto-suficiencia para su legitimación, abarcadora de todos los ciudadanos sin importar su pertenencia a comunidades simbólicas (Habermas, 2006). Incluso a nivel motivacional, esta pertenencia básica permite eludir otra aspiración de unificación bajo un ideal de vida bueno y ejemplar según una tradición de- 
terminada. De este modo, la secularización del conocimiento y de la estructura de legitimación del poder serían suficientes para una base que permita una interacción entre ciudadanos de diversas procedencias, y también una adaptación condicional de la conciencia religiosa. Hasta este punto, parecería que la posibilidad de mediar y estabilizar las relaciones entre los ámbitos religioso y político ya tiene las herramientas necesarias. Sin embargo, Habermas ve que subsiste un peligro de otra índole, que notablemente acerca "lo político" a "lo religioso".

En su conferencia de Nueva York, Habermas muestra en las nociones de "lo político" y de "lo religioso" un parentesco por las nuevas influencias de la teología política, que reaparece como respuesta ante el capitalismo sistémico y la transformación de la política en administración, y la subsecuente despolitización generalizada de los ciudadanos y del ámbito público. Como luego elaborará en detalle en su última obra magna, Auch eine Geschichte der Philosophie, la formulación de "lo político" retrotrae a un sistema de pensamiento donde la cohesión social y la legitimación estaban dadas por un poder político que por su vínculo con lo religioso era capaz de conducir a la salvación y a la condena (Habermas, 2011: 25; 2019: 175ss). Pero las concepciones normativas de lo político en la antigua Grecia y en diversas manifestaciones de la llamada "era axial" comienzan a operar un cambio sustancial: el poder político ya no es manifestación de un poder divino, sino que es su "representante", y por ende se subordina a los representantes humanos a un tipo de nomos. También esta idea de representación es inviable desde la modernidad (aunque la noción misma de representación subsiste, extrapolándose a otras entidades). Pero, en todo caso, lo político significa "el orden simbólico de la autorrepresentación colectiva de las comunidades políticas en la imagen especular de los soberanos cuya autoridad estaba legitimada por un poder sagrado" (Habermas, 2011: 27).

La constatación de la "teología política" de las primeras décadas del s. XX es que ese movimiento no sólo ha perdido sus fuentes sino también su propia capacidad de configuración social. Y como veremos luego, la "nueva" "teología política" intenta asumir precisamente las condiciones de modernidad, pero inseminándolas con los contenidos semánticos y simbólicos para evitar su auto-despotenciamiento. Sin embargo, la respuesta de Habermas es diversa. Muestra cómo la influencia absolutista hobbesiana marcó la noción de representación y de política, hallando su más peligrosa expresión en la crítica de Schmitt a los Estados parlamentarios y su defensa de lo político al modo de una democracia de masas en un sistema autoritario. Luego, Habermas contrapone esta posición con el liberalismo de Rawls, e intenta finalmente retomar el sentido de "lo político" y su vínculo con "lo religioso" en el marco de la democracia liberal. 
Conviene aquí recuperar los principales resultados del análisis habermasiano.

En primer lugar, Habermas desmiente la descripción de Schmitt, ya que lo teológico mismo es la fuente de la ruptura moderna por la guerra entre confesiones. Y, por otro lado, la "privatización" que surge con la modernidad no elimina el poder de agencia de los ciudadanos, sino que, por el contrario, termina comprendiendo la configuración del Estado y su representante a partir de la confluencia de esas unidades individuales. Esto abonaría un primer elemento de Habermas, en tanto lo "impersonal" de la dimensión normativa sí podría expresar una serie de voluntades que confluyen en cierta unidad. En segundo lugar, el decisionismo de Schmitt y el autoritarismo que abonaba, con las consecuencias nefastas que tuvo en su concreción histórica, parece haber eliminado toda posibilidad para cualquier teología política. Pero Habermas propone una serie de criterios para identificar qué puede ser rescatado en esta -según él"problemática" tradición.

Para evitar confusiones, Habermas introduce la noción de "postsecularismo", con el objeto de diferenciar, por un lado, entre secularización del Estado y secularización de la sociedad, y por otro, entre contenidos simbólicos o éticos y su manifestación aceptable en una era postmetafísica. Ambas vías le permitirían sostener una religiosidad persistente (incluso creciente) de la sociedad y los reclamos de legitimación no comprometidos por esas exigencias simbólicas, y por otro la reubicación de los niveles de sentido en un plano que no afecte las exigencias de una sociedad liberal republicana. Pero en su defensa de este modelo moderno, Habermas debe dar una respuesta a la reaparición de "lo político" y sus vínculos con la teología política. Comienza su respuesta afirmando, a partir de Rawls, que entre personas de diversas pertenencias confesionales es menos importante su "overlapping consensus" que cómo hacen uso público de la razón para conseguirlo. De este modo, las tradiciones religiosas podrían permanecer en el marco de las discusiones políticas públicas siempre que se atengan a ese uso público y sus reglas.

Pero "lo político" y la "teología política" seguirán siendo sospechosas en tanto preserven "las connotaciones metasociales de cualquier tipo de autoridad estatal" (Habermas, 2011: 33). La posición de Habermas es la exigencia procedimental de traducir las comprensiones propias en expresiones admisibles por quienes no comparten el conjunto de creencias propio. Sería una carga epistémica y práctica simétrica, puesto que también exigiría de quienes no poseen esas creencias el aprendizaje de valorar nociones sin importar su procedencia, recuperando intuiciones morales provenientes de otras cosmovisiones. 
Pero al terminar su análisis y propuesta, Habermas afirma que lo que Schmitt temía se ha consolidado. El poder político ha perdido toda figura personal, se ha impuesto una idea procedimental vacía del ejercicio político, y se han cortado los lazos con las tradiciones religiosas. Si bien esta última afirmación debería ser revisada a la luz de lo sucedido en los últimos años, parece consistente que la inmersión total en los procedimientos, incluso de los sectores religiosos que recientemente han asumido un protagonismo público, ha perdido el sentido de la justicia escatológica y las sensibilidades que las tradiciones religiosas, en particular el monoteísmo judeocristiano, portaban consigo (Habermas, 2011: 37). Estas sensibilidades permitirían a la democracia postsecular moderna y constitucional aprovechar esas tradiciones en condiciones históricas cambiantes y proponer un universalismo que reconozca múltiples culturas pero que mantenga un sentido universalista de los derechos humanos. Hasta aquí Habermas. Pero subsiste la pregunta de si con este "cierre" y subordinación de lo teológico-político a la socialización comunicativa, y eventualmente la recuperación de sus sensibilidades frente al sufrimiento y su defensa de la dignidad humana, concluye su aporte. El intento de este trabajo es recuperar una tensión más fundamental del problema del rol de lo religioso en lo político, donde la tensión se extrapola a lo religioso mismo, rompe sus connivencias, y eventualmente permite que surja otro tipo de autoridad que se legitima políticamente, pero desde otro lugar que la preocupación por el gobierno. Para ello sirve volver a plantear el problema desde la teología política, y a partir de esa repetición identificar otras respuestas posibles.

\section{LA LEGITIMIDAD DE EKKLESLA Y OIKUMENE: SCHMITT}

Schmitt significa la revitalización y actualización de la teología política. Es sabido que su discípulo y contrincante, el teólogo Erik Peterson, hablaba ya en 1935 de la "liquidación" de la teología política, pues aunque mantenía un carácter público para la Iglesia (contra el espiritualismo o la iglesia apéndice del Estado luteranos), no aceptaba que el mismo fuera del modo de una legitimación trascendente de las acciones históricas, ni de un principio de soberanía que permitiese decidir sin otro recurso que a la autoridad propia, ni finalmente que se recurriera a un estatismo inadmisible en una sociedad plural y democrática. Pero dicha "liquidación" no fue tal. No sólo porque Schmitt sobrevivió a su propio nazismo sin claudicar en su idea de legitimidad basada en la soberanía de la decisión, sino también porque siguió siendo un referente para pensadores de las más diversas procedencias ideológicas. De todos modos, el objeto de este apartado es abordar el problema de la legitimidad y la ten- 
sión que el mismo establece entre el orden interno de la Iglesia y el orden político organizado u Oikumene. Rosenzweig (1997: 415-417), coetáneo de Schmitt, es claro al plantear el problema, aunque aplicándolo sólo a los países cristianos: para los cristianos hay una doble vía, Iglesia y Estado, que desde el principio están separados, a diferencia de la polis griega pero también de las teocracias, aunque al mismo tiempo entran en relaciones cambiantes de apoyo u oposición. Ambos, Estado e Iglesia, se conciben parte del mundo. Ambos se inscriben en un ordenamiento jurídico. Pero ninguno es el Reino de Dios mismo, ninguno es la plenitud. De allí que los riesgos cristianos sean la espiritualización que elimina todo compromiso material, la humanización que fija en estructuras humanas lo divino, y finalmente la mundanización de lo divino que elimina toda trascendencia (Rosenzweig, 1997: 471). Por eso se necesita del judaísmo como pueblo "al margen" de la historia, que muestra que todo intento de preparar las condiciones para una historia redimida es necesario, pero siempre limitado, nunca plenamente realizado. El monoteísmo impone una ruptura de la Ecumene, entendida como una totalidad en reposo, en la que Imperio y mundo no se distinguen (Rosenzweig, 1997: 97). El cristianismo surgido del judaísmo y su ampliación por el Imperio pone en crisis precisamente dicha noción, e impone la pregunta por las legitimidades de su propia estructura, Ekklesía, y de la Oikumene imperial en que se insertó.

Schmitt afirma que por el catolicismo se da una complexio oppositorum única, capaz de evitar tanto el espiritualismo como el gnosticismo. Esta composición se da por la noción de "representación" (Schmitt, 2011, 10), por la que las autoridades "reciben" su potestad de un campo trascendente que les supera, les da sentido, potestad y límite. Ninguna autoridad terrena tiene su origen en sí misma. El derecho canónico que se construyó sobre esta noción fue, según Schmitt, la base sobre la que se erigió el Estado moderno. En este sentido, ningún orden político per se sería legítimo, pero sí puede serlo cuando asume la representación de la voluntad divina. La legitimidad nacida en la noción de representación hacía que la política tuviera un sostén teológico. Es notable identificar cómo esta concepción funcionó en documentos eclesiales antes del Vaticano II en su condena de diversos modelos políticos de la modernidad, y cómo cae la misma con el propio Vaticano II en su intento de reivindicar no ya una política particular sino las condiciones de posibilidad que toda política debería cumplir para no contradecir principios cristianos ${ }^{5}$. Y la

5 Siguiendo el estudio de José Luis Villacañas (2009: 142-154), el Vaticano II representaría la derrota final de Schmitt y la victoria póstuma de Peterson, mostrando además la contradicción interna de quien afirma que la obediencia al representante debe 
secularización fue el proceso que permitió que aquella representación de lo divino sea vaciada, a pesar de que se busca en la modernidad el mismo impulso legitimatorio, pero $\sin$ la noción de trascendencia que le era imprescindible.

Lo central de toda teología política es la no-autarquía del sujeto. Aquí se identifica un elemento anti-ilustrado de carácter ambiguo, pues puede devenir en políticas totalitarias o en pensamientos débiles posmodernos. Pero la pregunta de Schmitt no es cómo se constituye una comunidad sino cómo se relacionan autoridad y obediencia mundanas en vistas a la idea de que todo poder procede de Dios. Sin embargo, en ese modelo "conservador" sucede algo notable, porque así "el cristiano ha minado la autoridad secular con su reconocimiento de un nuevo fundamento de la misma" (Schmitt, 2011: 58). La no autarquía del sujeto y la ausencia de fundamento de la legitimidad del orden gubernamental en sí misma conlleva pensar en la legitimidad de toda decisión en una estructura jerárquica trascendental. Esta estructura hace que los bienes representados se transformen en cargos, al tiempo que los cargos son separados de las personas que los detentan (Schmitt, 2011: 61). La consecuencia parece clara: nadie es legítimo poseedor de un cargo por sus habilidades o sus capacidades, menos aún por ser artífice de la propia legitimidad, sino que ésta es concesión externa.

Sabemos que hubo una recepción de derecha y una de izquierda de la obra de Schmitt, y que la idea de no-autarquía es fecunda en interpretaciones a menudo contradictorias. Al mismo tiempo hay algo que Schmitt permite reconocer, aunque se niegue a aceptar. Se trata de los elementos "anarquistas" o en lenguaje bíblico "proféticos", que niegan a los poderes fácticos consumarse como representantes absolutos de lo Absoluto. Son estos elementos los que es preciso recuperar para entender el rol que dan a los desposeídos y humillados ante el estado de cosas impuesto por los poderes fácticos. $\mathrm{Y}$ aquí se muestra incipientemente un primer rol posible para la teología política en condiciones de legitimación moderna. Pero ¿qué debería forzarnos a hacerlo? ¿Qué sentido podría aún tener esta noción de autoridad por vía de representación en una sociedad inmanentista y sin referencia trascendente que sea globalmente significativa? ¿Cuál es la "legitimidad" de aquellos que carecen de toda legitimación fáctica?

La teología política, dice Taubes, no tiene sentido en una época en que la fe religiosa ha perdido su rol - siendo a menudo suplantada por otros desarrollos como la teozoología racista (Taubes, 2007: 189), y otras

primar en la comunidad de fe -Schmitt- a pesar de tener y tomarse la libertad de contradecir la doctrina conciliar. 
justificaciones inmanentistas como los neo-biologismos. Pero precisamente por eso, Schmitt nos obliga a plantear nuevamente el significado de la legitimidad, y a recordar que la versión moderna responde a una estructura previa y secularizada. A menos que lo nuevo sea siempre sin referencia a lo anterior, y con Blumemberg se conciba toda mirada atrás como un déficit en la propia conciencia de legitimación científica. Pero no mirar atrás puede también significar no mirar al costado y a las consecuencias prácticas -sociales, económicas, morales, políticas- que dicha conciencia tiene. Frente a la caída de la "revelación", las instituciones provistas ante el dilatamiento del tiempo final ya no parecen ser un Katechon en vistas de otro tiempo por llegar, sino relaciones sociales de pleno derecho, sin una medida exterior a sí para su juicio.

\section{LA BÚSQUEDA DEL ORDEN EN LA HISTORIA: VOEGELIN}

Taubes (2007: 159) llama a Schmitt "apocalíptico de la contrarrevolución", porque muestra que el Estado moderno se erigió sobre las bases construidas por la Iglesia frente a la realidad de que el "tiempo final" esperado no se concretaba, y sin embargo seguía siendo necesario gestionar la ley en el seno de las realidades concretas del mundo. Y a pesar de que Schmitt tuvo muchos lectores contrapuestos, está claro que una de las líneas de recepción más influyentes se dio en Estados Unidos, a partir de exiliados alemanes ${ }^{6}$. Entre ellos, y en un claro intento de generar una antítesis a Schmitt que al mismo tiempo es heredera de su planteo, se encuentra Eric Voegelin. Voegelin entiende que la mayor crisis de legitimación de la política en su época está dada por la desintegración del sentido. Esta desintegración nace con la caída de un modo de conocimiento metafísico que podría inteligir un orden y un telos en el mundo. A pesar de que su noción de "religión política" (Voegelin, 2000a: 19) está en confrontación directa con la posición legitimatoria que Schmitt daba a la "teología política", no son demasiado distintas las opiniones de ambos sobre el origen y las consecuencias de la secularización. Voegelin entiende que hay una construcción mística del significado social en todas las políticas totalitarias, una suplantación de la experiencia religiosa por la política, y sin embargo es precisamente la experiencia de un realissimum de un cuerpo colectivo la que caracteriza a la religiosidad.

El artículo de 1938, "Las religiones políticas", es un temprano intento de mostrar el riesgo presente en los modelos de legitimación que estructuralmente son idénticos al religioso, en tanto no permiten separar

Desde la perspectiva de la "historia de los efectos", probablemente la influencia más importante se da en Leo Strauss (McAllister, 1995; Meier, 2006). 
poderes, ni valorar al individuo, ni separar lo sacro de lo mundano. Al mismo tiempo, Voegelin sostiene la necesidad de una recuperación de la metafísica para posibilitar una nueva fundamentación del orden en la historia. Para ello afirma que hay verdades comunes y niveles del ser que se han conseguido en el proceso histórico. Hay una "edad ecuménica", en que el orden logrado muestra a la Historia como proceso de una $\mathrm{Hu}-$ manidad Universal, con estructuras que trascienden a cada realización o grupo particular. Hay aquí una posición claramente hegeliana, pero no es ésta el centro de interés en este trabajo, sino otro aspecto también ligado con la dialéctica. Voegelin propone recuperar un sistema simbólico que dé sentido a las instituciones que perdieron sus contextos simbólicos de validación. Pero hay una consecuencia fundamental: esas instituciones deben ser eficaces, y esto puede a menudo significar una contradicción con el marco simbólico. Es el problema de los medios injustos para la realización de un fin.

Voegelin ve en el interior de nuestras acciones políticas concretas una "tensión existencial": quien toma una decisión, sobre todo pública, debe saberse al mismo tiempo representante de una sociedad y funcionario en vistas de una finalidad (Voegelin, 2000a: 109-148). Un primer movimiento de injusticia podría estar en la negación de las responsabilidades inherentes a esa doble función. Pero podría incluso suceder que se mantuviera en vista un reaseguro simbólico y las demandas morales provenientes del mismo, y sin embargo los medios empleados en la acción no fuesen justos. La dificultad radica en que, en los diversos intentos de generar un orden social determinado, como por ejemplo en la Ecumene imperial, no fue la sociedad un sujeto de orden sino sólo un objeto de conquista, y el "orden" sólo una imposición (Voegelin, 2000b, 179). Si esto sucede, el orden no surge ni condice con la supuesta condición espiritual genuina, sino que es un modo de "mal", o sea una acción que no condice con la realidad espiritual en sentido de Voegelin (Casanova, 1997: 321). Pero independientemente de posiciones concretas, Voegelin ve que en toda política hay tipos de acción que pueden ser moralmente problemáticos por su vinculación con el mal. Es el gnosticismo -según Schmitt un recurrente enemigo de toda teología política, según Voegelin inseparable de la política y filosofía del siglo XX- quien quiere negarlo, partiendo de un "no-reconocimiento de la realidad", o sea, de la difícil y casi nunca plenamente conseguible coordinación de medios y fines justos, y por tanto del razonamiento prudencial siempre peligroso y revisable (Voegelin, 2000a: 226). Todo reordenamiento social debería, según Voegelin, expresar adecuadamente las fuerzas existenciales reales, pero de hecho la libertad y la prudencia necesarias implican la posibilidad del conflicto, así como en ocasiones el uso de la fuerza. Ahora bien, ¿cómo 
mediar entre las fuerzas imperantes y las emergentes con sus reclamos, su falta de "orden” y su necesidad? Más aún, ¿cómo establecer cuáles de las fuerzas emergentes posee una aceptabilidad que pueda denominarse legítima, y cuáles esgrimen sólo la legitimación del poder fáctico?

\section{LA MEMORIA DE LA LEY Y DE LA PASIÓN: TAUBES Y METZ}

La "teología política" en las diferentes lecturas de Schmitt y Taubes no sólo muestra el origen trascendente de la noción de legitimidad, así como la admisión de que en el Katechon el orden no puede tener la pureza aspirada por el gnosticismo, sino también permite una crítica a las estructuras aparentemente legitimadas del orden. Es así que, a partir de la teología política de Schmitt, Taubes (2007: 187) muestra algo inquietante: per se democracia, cesarismo y dictadura no se contradicen necesariamente. Más aún, afirma que las políticas de la inmanencia y la legitimación establecida al interior del mundo pueden perfectamente relacionarse con la desigualdad y de la criminalización del extraño (Taubes, 2007: 143. 188). Y finalmente a partir de esta crítica se desenmascaran las posiciones más "tecnocráticas" del orden jurídico, pues éste también existe y se legitima de alguna manera en los despotismos (Taubes, 2007: 192). Se trata claramente de un desafío para nuestras democracias modernas, que a menudo parecen transformarse en un fin en sí, en una visión "acabada" de sí mismas y de la historia. Es precisamente lo religioso lo que pone límites a esta pretensión. No se trata del reemplazo de un ámbito por otro, lo que redundaría en otra reducción. Se trata de indagar el lugar desde donde se pueda ejercer una crítica a las estructuras vigentes en su aparente legitimidad.

Metodológicamente Taubes recupera el valor del "sentido alegórico" (2007: 58). La crítica historiográfica tradicionalmente ligada con la teología política tiene un valor limitado, pues al desconocer otros sentidos metafóricos y simbólicos posibles quita un potencial transformador a las tradiciones religiosas, más allá del marco epocal donde les toque actual (incluidas las condiciones de legitimación modernas). Por ello Taubes recupera de Pablo dos elementos fundamentales: su concepción apocalítptico-escatológica y su transfiguración mesiánica de la ley. Además, Taubes (2007: 75) contrapone esa lectura simbólica con la versión liberalracionalista de la religión, que cae con la barbarie nazi ${ }^{7}$. Por su parte, el valor alegórico y simbólico de la tradición religiosa implica siempre un retorno a la memoria, y lo ve en Pablo, porque la renovación de la Ley en éste es precisamente no una superación sino una actualización. En pri-

Rosenzweig ya la veía caduca con la caída del $2^{\circ}$ Reich. 
mer lugar, Pablo piensa a la luz del eschaton, y de un eschaton que al mismo tiempo se espera y ya sucedió: fue la inversión de todos los valores del mundo, ya que el nomos no es el imperator sino el crucificado. Y en esta "carga política que es puro material explosivo" (Taubes, 2007: 39), Taubes muestra también que toda renovación de la Ley depende de la memoria de una trascendencia que antecede e inspira toda concreción legal. Por este fin de los tiempos y esta renovación de la Ley, Pablo ve a la Ekkelesia no como una polis autónoma en el seno del Imperio, ni mucho menos como una religión legalizada entre otras, sino como un nuevo orden universal que pone en cuestión toda otra constitución histórica del orden. Y la insubordinación al orden imperante y la reformulación de la Ley se da en el mandamiento del amor, como la demanda en la que todo se resume y que a su vez funda la posibilidad de un cuerpo común (Taubes, 2007: 66).

Ahora bien, hay en esta lectura una doble dificultad con la que se debe lidiar, si es que esta posibilidad religioso-política ha de tenerse en cuenta: el contexto de pluralismo contemporáneo y la situación de opresión, particularmente en los llamados "países periféricos". De hecho, Taubes critica a los pensadores que analizan lo político desde lo religioso en América Latina, porque según él "trivializan" a los filósofos marxistas y vinculan al marxismo con lo religioso, siendo que el marxismo "se traga toda sustancia religiosa" (Taubes, 2007: 168). Al mismo tiempo reconoce el problema que tiene la noción de legitimidad en un contexto de pluralidad, en el que a lo sumo se puede reclamar legalidad, pues las condiciones para la legitimación no estarían dadas (Taubes, 2007: 143-144). En ambos argumentos la cosa es tanto peor para los desposeídos de la tierra, pues ni tendrían ya la posibilidad de apelar a un orden trascendente, ni les quedaría revelarse -so pena de ilegalidad-contra el orden imperante. Más allá de la opinión de Taubes respecto del marxismo, no es casual que quienes sufren esta situación apelen al plus que Habermas ve en lo religioso: más que a una ética o un reconocimiento legal es la esperanza de una redención (Habermas, 2006: 258). Y por eso mismo Chantal Mouffe (2006: 318) argumenta que las "identidades posconvencionales" no hicieron obsoletas a las formas religiosas de identificación, que aún reclaman no-neutralidad estatal ante dilemas, que entienden mejor que muchas posiciones liberales la dimensión agónica y polémica de lo político, y que finalmente asumen así un rol legítimo de demanda y desafío. De allí que sea plausible la formulación de quienes identifican su situación de opresión con la memoria del sufrimiento y la redención que el mesianismo monoteísta portó consigo, y esto en un contexto no de Christianitas sino de caída del relato único judeocristiano y su reemplazo 
por una sociedad plural. Esa formulación fue el objetivo de la teología política de Metz.

En el fragmento 217 de Más allá del bien y del mal, Nietzsche llama bienaventurados a los que olvidan. Metz le considera por ello el profeta de aquello que se llamó posmodernidad, por esa creencia en una amnesia que sanaría heridas, por oposición tanto al mandato bíblico del recordar, zachor (Yerushalmi, 1982), como sobre todo ante la memoria de la pasión y muerte en la historia (Metz, 2013: 18). Sucede que la memoria aparece en la tradición monoteísta como un mandamiento. Si la sociedad capitalista se caracteriza por aniquilar las diferencias y homogeneizar el tiempo y el espacio, es en los pensadores de la excepción donde se debate la posibilidad de encontrar casos o situaciones extraordinarias desde las cuales dotar de sentido a lo cotidiano y sostener los reclamos de los despojados. La tradición de la teología política surgida de Schmitt busca el lugar de la excepción (del soberano) como punto de partida del razonamiento y la universabilidad, y como heredero de esta posición Metz la reformula, encontrando en el sufrimiento ajeno el lugar hermenéutico desde el cual reconstruir una universalidad que de hecho no parte de relaciones discursivas simétricas (Ruz, Rosolino \& Schickendantz, 2008: 590). Esta memoria passionis es estructuralmente unívoca con la pasión de Israel y la pasión Jesuana, como también lo es con la demanda de liberación y redención por la que claman. Pero, ¿qué rol puede tener esta memoria a nivel político que no sea sólo el de una "provocación" o la inspiración motivacional e intuición moral admitida por Habermas?

El sufrimiento encarnado, concreto e histórico significa siempre un "correctivo" a los sistemas instalados. En primer lugar, porque recuerda que realmente hay sujetos históricos y situado, que la subjetividad no es deconstruible a voluntad. Pero además que esa subjetividad no es sólo la de individuos, sino que hay colectivos -y Metz (1979: 146) utiliza no sin valentía la palabra "pueblo", en un contexto en que seguramente esa palabra evocaba otras experiencias- que se configuran como sujetos históricos. Y esa configuración se da mediante un uso particular de la memoria y de la narración. El recuerdo del sufrimiento y del anhelo de liberación permite vincular una visión interpretativa del mundo con una crítica posible y claramente dirigida. Metz no desconoce el carácter problemático y "peligroso" tanto de la constitución de esas subjetividades sociales como del uso crítico de la memoria. Pero ese peligro es moneda cotidiana para la teología política, que no se debe despreciar sino saber acotar.

Uno de los modos de delimitar el peligro es distinguir laicismo de pluralismo (Metz, 2007: 196). Para Metz, en el caso europeo existe el riesgo de pensar que una política anti-religiosa garantizaría la pluralidad, 
cuando de hecho la destruiría. Tal destrucción sería un modo de amnesia, que con el objetivo aparente de garantizar un reconocimiento a otras tradiciones quitaría las posibilidades dialécticas de confrontación, comparación y juicio. Y un adecuado uso de la memoria -en especial de la memoria de los sufrimientos causados, por ejemplo, por algunas versiones del universalismo- permitiría un juicio sobre cada uno de los modelos de institución y de los valores que les sostuvieron.

\section{A MODO DE CONCLUSIÓN: LA AUTORIDAD DE LOS QUE SUFREN}

Las críticas de Habermas a la teología política, así como las expresiones actuales de lo religioso indican una serie importante de dificultades de integración en las sociedades contemporáneas. Sin embargo, la teología política puede hacer una revisión del vínculo con lo político, al modo que se expresó en el pasado, y actualizarlo en condiciones contemporáneas a partir de la tradicional tensión entre lo escatológico y lo "administrativo" (katechon). Y puede hacerlo, en el caso del monoteísmo judeocristiano, apelando precisamente a una de sus posiciones estructurales, esto es el reclamo de los sufrientes.

Esta revisión muestra cómo una de las versiones más influyentes del vínculo religioso-político es aquella que defiende el rol legitimatorio de la "religión civil" en el marco del Estado moderno. La explicación es simple: si bien el Estado crea su propia legitimidad, la religión puede coadyuvar al cumplimiento de sus leyes, fundamentándolo desde otra perspectiva. Por eso Taubes escribe no sin ironía: "El interés por el poder del Estado se da también, desde luego, en el cristianismo. Se reza por la conservación del Estado, porque, Dios no lo quiera, si no permanece, irrumpe el caos, o, aún peor, ¡el Reino de Dios! Sería esto lo peor que podría pasar" (Taubes, 2007: 84). Parece innegable que el marco metafísico que validó el surgimiento y afianzamiento de la visión religiosa del mundo ha caducado, al ser reemplazado por la comprensión científica y su eliminación de toda teleología, de toda pregunta por el origen y del problema del sentido en la inmanencia. Y sin embargo no es la primera vez que la tradición monoteísta se reformula a sí misma. Una lectura simplista sería porque sus aparatos de poder están muy enraizados, y que el Gran Inquisidor -admiración de Schmitt- hizo muy bien su trabajo. Pero una lectura más interesante, que no elimina esa hipótesis, pero la complejiza, es que hay la experiencia de la memoria de una vocación y una promesa en el monoteísmo que fuerza a intentar actuar públicamente, y al mismo tiempo a poner en cuestión cada una de las actuaciones e instituciones conseguidas. Al decir de Rosenzweig (1997: 273) el Reino, en tanto sociedad humana en plenitud de justicia, crece con la acción 
humana al tiempo que "es siempre futuro, pero es futuro siempre". La memoria de una Ley imposible y de un sufrimiento a menudo olvidado es el reaseguro de que todo intento de comprender un determinado orden político como acabado será refutado, y al mismo tiempo que todo intento tecnocrático de "calmar" las pasiones religioso-políticas fracasará. No fracasará sólo porque estamos constituidos por la finitud que es el pasto del que se alimenta la religión, sino porque hay un hambre de justicia y plenitud que ninguna realización -ni religiosa ni política- sacia.

¿Para qué retomar las cuestiones vinculadas con la legitimidad, el orden y la memoria? Más aún ¿por qué hacerlo desde autores ciertamente vinculados pero representantes de posiciones tan disímiles? ${ }^{8} \mathrm{El}$ argumento es que ellos reivindican que la cuestión del sentido no puede ser ajena a la praxis política, que no todos los logros técnicos "pacificantes" o antipolémicos de la comunidad política conllevan necesariamente un carácter de legitimidad, y finalmente que los aspectos dialécticos que nuestra época contemporánea pretendía ver superados son parte ineludible de una búsqueda seria de la justicia. Desde este punto de vista, la política como técnica no es suficiente para dar cuenta de lo que se abre en su vínculo con lo religioso, pero tampoco lo es la posición de Arendt que comprende lo político como el espacio de acción y expresión de los libres, dejando de lado las otras preocupaciones "materiales" previas.

Uno de esos aspectos es el de la memoria, en especial de la memoria del dolor y sufrimiento. Todo ello se centra en la idea de que es necesaria una autoridad a la hora de la decisión, a pesar de que hayan caducado las posiciones que las metafísicas fundamentaron hasta la modernidad. Y sin embargo se revela con una paradojal autoridad la memoria de la pasión. Los autores empleados tienen una perspectiva situada en Europa, y a pesar de que toman como modelo del sufrimiento algunos acontecimientos también europeos - piénsese en Auschwitz como lugar por antonomasia de reflexión sobre el sufrimiento y el mal- la estructura que proponen se ve ciertamente enriquecida por otros sufrimientos tan extendidos como olvidados, como las tragedias diarias en nuestra América. Y el vínculo de subjetividad, memoria y praxis teológico-política parece aquí muy claro, como sucede con el evento que estas jornadas recuerdan. También claras aparecen las dificultades que el entramado religiosopolítico trae consigo, como las dificultades de la opción que Todorov (2004: 53-127) reconoce en situaciones límite: el martirio del héroe y

8 Schmitt sería el representante de extrema derecha antiparlamentaria, Voegelin el del conservadurismo de centro, Taubes el de un pensamiento judío de izquierda, y Metz finalmente un pensamiento social-cristiano, aunque haya sido llamado "liberal" por algunos teólogos de la liberación. 
santo contra la ardua y cotidiana negociación de quien intenta mantener la vida, con todas sus ambigüedades. El valor del sufrimiento no es el de un argumento apodíctico o la evidencia de un hecho que fuerce la aquiescencia de la razón. No tiene un valor probatorio para los órdenes lógicos o epistemológicos imperantes. Pero tiene la paradojal fuerza de algo que se impone aún cuando está en riesgo constante de olvido. Tiene la fuerza de lo débil.

\section{REFERENCIAS}

Casanova, J. (1994). Public Religions in the Modern World. Chicago: Chicago University Press.

Casanova, C. A. (1997). Verdad escatológica y acción intramundana. La teoría política de Eric Voegelin. Pamplona: Eunsa.

Cohen, H. (2004) La religión de la razón desde las fuentes del judaísmo. Barcelona: Anthropos.

de Vries, H., \& Sullivan, L. E. (2006). Political Theologies. Public Religions in a PostSecular World. New York: Fordham University Press.

Dussel, E. (2019). Entrevista de Carmen Aristegui a Enrique Dussel. Disponible en https://aristeguinoticias.com/1411/mexico/expone-dusseltrasfondo-de-la-ideologia-evangelista-para-justificar-golpes-de-estadovideo/

Dussel, E. (2020). Siete ensayos de filosofía de la liberación. Madrid: Trotta.

Habermas, J. (2006). On the Relations Between the Secular Liberal State and Religion. En H. de Vries y L. E. Sullivan (Eds.), Political Theologies. Public Religions in a Post-Secular World (pp. 251-260). New York, Fordham University Press.

Habermas, J. (2011). Lo político: el sentido racional de una cuestionable herencia de la teología política. En E. Mendieta y J. VanAntwerpen (Eds.), Elpoder de la religión en la esfera pública (pp. 23-38). Madrid: Trotta.

Habermas, J. (2019). Auch eine Geschichte der Philosophie. Band 1 Die okzidentale Konstellation von Glauben und Wissen. Berlin: Suhrkamp.

Heidegger, M. (1996). Caminos de bosque. Madrid: Alianza.

Lübbe, H. (1986). Religion nach der Aufklärung. Graz/Wien/Köln: Styria.

Lyotard, J.-F. (1979). La condition postmoderne: rapport sur le savoir. Paris: Les Éditions de Minuit.

McAllister, T.V. (1995). Revolt against Modernity. Leo Strauss, Eric Voegelin, \&o the Search for a Postliberal Order. Kansas: University Press of Kansas.

Manemann, J. (2002). Carl Schmitt und die Politische Theologie. Politischer AntiMonotheismus. Münster: Aschendorff.

Meier, H. (2006). Carl Schmitt and Leo Strauss: The Hidden Dialogue. Chicago: The University of Chicago Press.

Metz, J.-B. (1979). La fe, en la historia y la sociedad. Esbozo de una teología política fundamental para nuestro tiempo. Madrid: Ediciones Cristiandad. 
Metz, J.-B. (2007). Memoria passionis. Una evocación provocadora en una sociedad pluralista. Santander: Sal Terrae.

Metz, J.-B. (2013). Two-Fold Political Theology. En F. Schlüsser Fiorenza (Ed.), Political Theology. Contemporary Challenges and Future Diretions (pp. 1322). Louisville, KE: Westminster John Knox Press.

Mouffe, Ch. (2006). Religion, Liberal Democracy, and Citizenship. En H. de Vries y L. E. Sullivan (Eds.), Political Theologies. Public Religions in a PostSecular World (pp. 318-328). New York, Fordham University Press.

Rosenzweig, F. (1997). La Estrella de la Redención. Salamanca: Sígueme.

Ruz, M.; Rosolino, G., \& Schickendantz; C. (2008). Razón anamnética, sufrimiento ajeno y teodicea. Claves de lectura, logros y límites de la obra de Johann Baptist Metz. Teología y Vida, XLIX(4), 575-603.

Schmitt, C. (2009). Teología política. Madrid: Trotta.

Schmitt, C. (2011). Catolicismo romano y forma politica. Madrid: Tecnos.

Scott, P., \& Cavanaugh, W.T. (2005). The Blackwell Companion to Political Theology. Malden/Oxford: Blackwell.

Todorov, T. (2004). Frente al limite. Buenos Aires: Siglo XXI.

Villacañas, J. L. (2009). La leyenda de la liquidación de la teología política. En C. Schmitt, Teología política (pp. 135-180). Madrid: Trotta.

Voegelin, E. (2000a). "The Political Religions", The Collected Works of Eric Voegelin (Vol. 5). Missouri: University of Missouri Press.

Voegelin, E. (2000b). Order and History IV, The Ecumenic Age, The Collected Works of Eric Voegelin. (Vol. 17). Missouri: University of Missouri Press.

Weber, M. (2014). Economía y sociedad. México D.F.: Fondo de Cultura Económica.

Yerushalmi, Y.H. (1982). Zakhor: Jewish History and Jewish Memory. Washington: The University of Washington Press. 